\title{
A Novel Pre-Synchronization Control for Grid Connection of Virtual Synchronous Generator
}

\author{
Xuhai Chen ${ }^{1}$, Yiwang Zhang ${ }^{2}$, Jiqing Dong ${ }^{2}$, Xingkui Mao ${ }^{2, *}$, Jiaqiao Chen ${ }^{1}$, Buyin Wen ${ }^{2}$, Zhe Zhang ${ }^{3}$ \\ ${ }^{1}$ PowerChina Fujian Electric Power Engineering Co., Ltd, \\ Fuzhou, China \\ ${ }^{2}$ College of Electrical Engineering and Automation, Fuzhou University, \\ Fuzhou, China \\ ${ }^{3}$ Department of Electrical Engineering, Technical University of Denmark, \\ Kgs. Lyngby, Denmark \\ mxk782@fzu.edu.cn
}

\begin{abstract}
The virtual synchronous generator (VSG) introduces rotational inertia and damping through the droop control to take part in frequency regulation of the grid. By building the VSG model, the VSG controller, including both the frequency controller and the excitation controller, are analysed and designed. The analysis shows that the large phase difference $\Delta \theta$ between the VSG voltage and the grid voltage at the grid-tied moment may produce large power and damage the VSG. The proposed pre-synchronization control minimizes the phase difference, which is implemented by replacing $\Delta \theta$ with $\sin \Delta \theta$ to avoid any step change from $\Delta \theta$. The proposed method is able to simplify control, shorten pre-synchronization tracking time, and achieve high accuracy without a phase-lock loop. The built $12 \mathrm{~kW}$ VSG simulation and prototype verify the theoretical analysis, the proposed control and its associated design.
\end{abstract}

Index Terms-Virtual synchronous generator (VSG); Pre-synchronization control; Droop control; Energy storage.

\section{INTRODUCTION}

As more and more distributed power sources are integrated into the power grid, their impacts on the grid are receiving more extensive attention. Grid-tied inverters, as power interface between the distributed generation and the grid, play the role of converting intermittent and fluctuated power from renewable energy sources into high quality and stable AC power. The traditional inverter control mainly includes constant power control (PQ control), constant voltage and frequency control (VF control), droop control, and so on. The inverter with PQ control can achieve constant output power, but does not have the grid frequency regulation [1]. The constant voltage control and the VF control make the inverter output of constant voltage, which is widely used in the island operation [2]. The droop control can make the inverter simulate some external characteristics of synchronous generator enabling the grid-tied inverter to involve in the grid system primary frequency regulation and voltage regulation, but the droop control does not have the capability of

Manuscript received 20 December, 2019; accepted 14 September, 2020.

This research was funded by China Power Construction Groups under Grant No. [DJ-ZDXM-2018-43] and Fujian Science and Technology Department under Grant No. 2018J01756, $2019 \mathrm{H} 0048$. providing damping and inertia for the system [3], [4]. In order to enable grid-connected inverters to provide more functions and services to the grid, such as the frequency and voltage regulation, black-start, etc., virtual inertia and virtual damping are introduced into the grid-tied inverter control strategy, and therefore they make the inverter act as a virtual synchronous generator (VSG) [5]-[7].

In order to avoid system damage due to excessive power impact of VSG at the moment of grid connection, it is necessary to realize the output voltage of VSG with the same voltage amplitude and phase as the grid during grid connection switching. This process is called "pre-synchronization control of VSG" [8], [9]. For the VSG grid connection switching control or the pre-synchronization control, in [10], an integral element is added in the active and reactive power droop control to realize the VSG to track the grid frequency and voltage with zero static error firstly. Then, the phase difference between the VSG voltage and the grid voltage is obtained by a phase-lock loop (PLL). Finally, the phase difference is superimposed on the VSG output voltage phase by the integrator to regulate the VSG phase and realize phase pre-synchronization between the VSG and the grid for the grid connection. In [11], the phase difference obtained by PLL is through a proportional-integral (PI) controller, then its error is directly superimposed on the VSG output frequency control, and the frequency and phase pre-synchronization control is carried out at the same time. In [12], the virtual impedance is introduced between the VSG and parallel connection nodes. When the virtual impedance angle is $90^{\circ}$ and the virtual active power is larger than zero, then the phase difference is zero, i.e., the VSG output voltage is completely in phase with the grid voltage, and the pre-synchronization control is completed.

In this paper, the basic model of VSG is established based on the previous study. Through its grid connection model, the power impacts at the moment of VSG grid-connection switching are analysed. Based on the traditional pre-synchronization control strategy, an improved pre-synchronization control strategy without PLL is obtained. Finally, the feasibility of the model and control method is verified by simulation and experiment. In order to 
smooth and shorten the VSG grid connection switching transient time, the new pre-synchronization control strategy is proposed in this paper.

This paper is structured as follows. After this introduction, Section II presents the VSG model, the VSG frequency controller, and excitation controller design. Section III analyses the VSG grid-tied switch transition and proposes the pre-synchronization control without PLL. In Section IV, the built $12 \mathrm{~kW}$ VSG is simulated. Section V presents a prototype, which has short pre-synchronization tracking time, high accuracy resulting in low power impact, and is implemented easily. Finally, Section VI gives the conclusions.

\section{THE VSG MODEL}

\section{A. Topology of Virtual Synchronous Generator}

The topology is shown in Fig. 1. In order to model the inverter as a synchronous generator, the fundamental components of the inverter output voltage $e_{a}, e_{b}$, and $e_{c}$ represent internal potential of the synchronous generator; $L_{l}$ in each phase is the corresponding synchronous reactance $L_{s}$ of the synchronous generator; the inverter output filter capacitor voltage $u_{\mathrm{ao}}$ is used to simulate the output voltage of the synchronous generator [13]. The block of VSG control algorithm is a key VSG controller. It includes the VSG output frequency controller and the excitation controller.

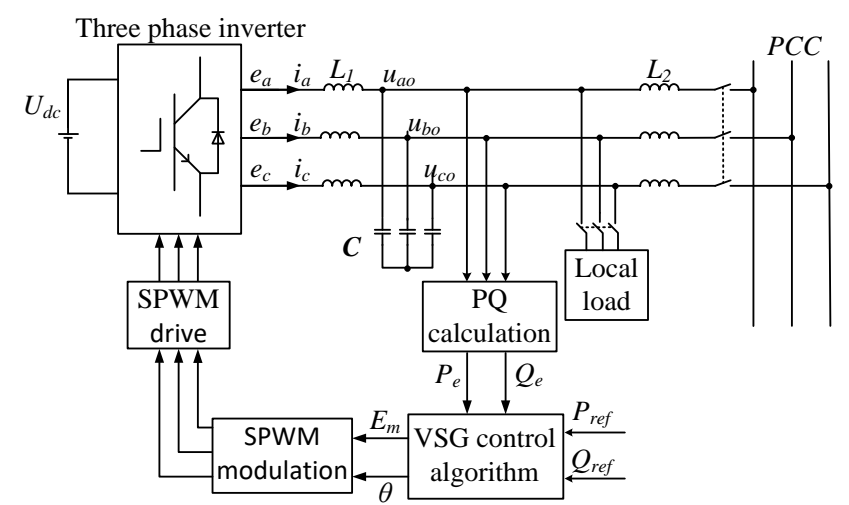

Fig. 1. Topology of the VSG main circuit.

\section{B. Design of the Frequency Controller}

The controller, based on the rotor motion equation of synchronous generator, makes the three-phase inverter to have the same output of the inertia and damping as a synchronous generator. Moreover, the droop control is introduced to enable the inverter to take part in primary frequency modulation of the power system [14]. The rotor motion equation can be expressed as

$$
T_{m}-T_{e}-D_{0}\left(\omega-\omega_{N}\right)=J_{0} \frac{d \omega}{d t},
$$

where $T_{\mathrm{m}}$ and $T_{\mathrm{e}}$ are mechanical torque and electro-magnetic torque of the synchronous generator, respectively; $D_{0}$ is the damping coefficient, $\omega$ is the rotor angular speed, $\omega_{\mathrm{N}}$ is the rated rotor angular speed, and $J_{0}$ is the moment of inertia.

Because $T_{\mathrm{m}}=P_{\mathrm{m}} / \omega$ and $T_{\mathrm{e}}=P_{\mathrm{e}} / \omega$, the rotor motion equation can be rewritten as

$$
P_{m}-P_{e}-D\left(\omega-\omega_{N}\right)=J \frac{d \omega}{d t}
$$

where $P_{\mathrm{m}}$ and $P_{\mathrm{e}}$ are mechanical power and electro-magnetic power of the synchronous generator, respectively, the damping and the moment of inertia are defined as $D=D_{0} \omega$ and $J=J_{0} \omega$, respectively.

The governor can control input mechanical power of the synchronous generator to make its output power and load reach balance again when the power system frequency shifts [15], and the modulation or the droop control equation is as follows

$$
P_{r e f}-P_{m}=-K_{p}\left(\omega_{r e f}-\omega\right),
$$

where $P_{\text {ref }}$ and $\omega_{\text {ref }}$ are the references of active power and output angular frequency, respectively, and $K_{\mathrm{p}}$ is the droop coefficient of active power.

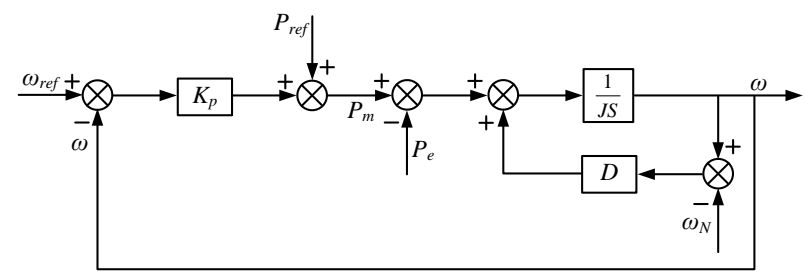

Fig. 2. Block diagram of the VSG frequency controller.

From (2) and (3), the frequency controller block diagram of VSG can be obtained. As shown in Fig. 2, the inverter output frequency rises gradually from zero to a steady value by the integral of $\omega$. Nevertheless, the control block diagram is complex, and the control method can be simplified further. Let $\Delta \omega=\omega-\omega_{\mathrm{N}}$, then we can get

$$
\frac{d \omega}{d t}=\frac{d \Delta \omega}{d t}
$$

Substituting (4) into the rotor motion (2), and the reference frequency $\omega_{\text {ref }}=\omega_{N}$, then the simplified frequency modulation or droop control equation is established as follows

$$
P_{r e f}-P_{e}-\left(K_{p}+D\right) \Delta \omega=J \frac{d \Delta \omega}{d t}
$$

Therefore, the VSG control can be simplified as shown in Fig. 3.

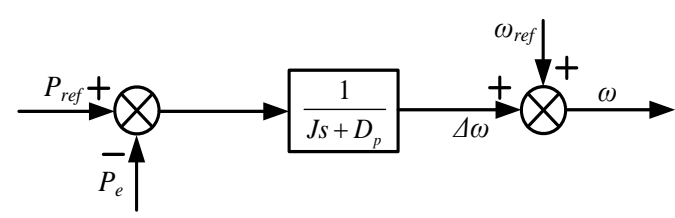

Fig. 3. Block diagram of the VSG simplified frequency controller.

\section{Design of the Excitation Controller}

The relationship between the internal potential and excitation current of synchronous generator is as follows 


$$
E_{m}=\omega M_{f} i_{f},
$$

where $M_{f}$ is the mutual inductance between the rotor and stator windings and $i_{f}$ is the excitation current.

In the control of synchronous generator, in order to keep its voltage constantly, the excitation controller is needed to regulate the excitation current in real time. The current control equation is

$$
i_{f}=G(s)\left(V_{r e f}-V_{o m}\right)
$$

where $V_{\text {ref }}$ is the reference voltage amplitude, $V_{\text {om }}$ is the inverter output voltage amplitude, and $G(\mathrm{~s})$ is the excitation regulator which equals to $1 / \mathrm{s}$.

Under the excitation current control, the droop control of synchronous generator will make the inverter output voltage decrease with the increase of reactive power [16], and we have

$$
Q_{r e f}-Q_{e}=K_{q}\left(V_{r e f}-V_{n m}\right)
$$

where $Q_{\text {ref }}$ is the inverter reactive power reference, $Q_{\mathrm{e}}$ is the output reactive power, $K_{\mathrm{q}}$ is the droop coefficient of reactive power, and $V_{\mathrm{nm}}$ is the inverter rated output voltage amplitude. The voltage reference value is adjusted by the change of output power regulating the output voltage of the synchronous generator.

Taking virtual mutual inductance $M_{f}=1 / K$, the control equation of the VSG excitation controller can be obtained with (7) and (8) as follows

$$
M_{f} i_{f}=\frac{1}{K s}\left(V_{n m}+\frac{1}{K_{q}}\left(Q_{r e f}-Q_{e}\right)-V_{o m}\right) .
$$

Therefore, from (9), the block diagram of VSG excitation controller can be obtained as shown in Fig. 4.

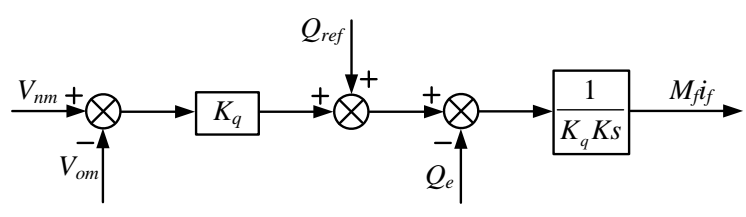

Fig. 4. Block diagram of the VSG excitation controller.

\section{VSG GRID-TIED TRANSITION}

\section{A. Grid-Tied VSG Model}

The grid-tied equivalent circuit of VSG is shown in the Fig. 5, where $U_{\mathrm{o}} \angle \Delta \theta$ is the VSG output voltage, $U_{\mathrm{p}} \angle 0^{\circ}$ is the grid voltage, and $Z=R+\mathrm{J} X$ is the line impedance.

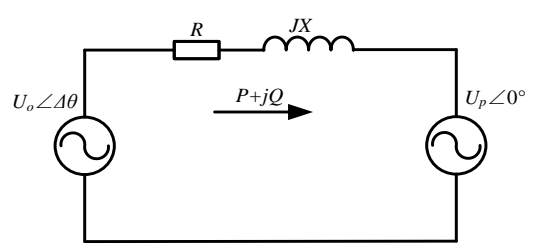

Fig. 5. Equivalent circuit of the grid-tied VSG.

Then, the VSG output current is

$$
\dot{I}=\frac{U_{o} \angle \Delta \theta-U_{p}}{R+j X}=\frac{U_{o} \cos \Delta \theta-U_{p}+j U_{o} \sin \Delta \theta}{R+j X}
$$

The output complex power can be calculated as

$$
\begin{aligned}
\bar{S}= & \dot{U} \dot{I}^{*}=\left(U_{o} \cos \Delta \theta+j U_{o} \sin \Delta \theta\right) \times \\
& \times\left(\frac{U_{o} \cos \Delta \theta-U_{p}-j U_{o} \sin \Delta \theta}{R-j X}\right) .
\end{aligned}
$$

Therefore, the output active power and reactive power of VSG are:

$$
\begin{aligned}
& P=\frac{U_{o}\left[R\left(U_{o}-U_{p} \cos \Delta \theta\right)+X U_{p} \sin \Delta \theta\right]}{R^{2}+X^{2}}, \\
& Q=\frac{U_{o}\left[X\left(U_{o}-U_{p} \cos \Delta \theta\right)-R U_{p} \sin \Delta \theta\right]}{R^{2}+X^{2}} .
\end{aligned}
$$

Given that the VSG output reactance $X$ is generally much larger than its resistance $R$, the above equations can be simplified as:

$$
\begin{gathered}
P=\frac{U_{o} U_{p} \sin \Delta \theta}{X}, \\
Q=\frac{U_{o}\left(U_{o}-U_{p} \cos \Delta \theta\right)}{X} .
\end{gathered}
$$

From (14) and (15), it can be seen that if the phase difference $\Delta \theta$ is too large at the moment of VSG grid connection, it will bring large active power impact. And when the grid voltage phase is leading of the VSG output voltage phase, the output active power will flow from the grid to the inverter so that the inverter will be damaged seriously. Therefore, in order to realize the VSG output voltage to follow the grid voltage amplitude and phase, it is necessary to carry out the pre-synchronization control when the VSG is tied to the grid, i.e., make the VSG output voltage follow the grid voltage amplitude and phase.

\section{B. Traditional Pre-Synchronization Control}

Before grid connection, VSG will output different frequency due to different load. Figure 6 shows the VSG output voltage phase of $\theta_{\mathrm{o}}$ and the grid voltage phase of $\theta_{\mathrm{p}}$ when the VSG output frequency $\omega$ is smaller than the grid frequency $\omega_{g}$. Figure 7 illustrates the phase difference, i.e., $\Delta \theta=\theta_{\mathrm{o}}-\theta_{\mathrm{p}}$.

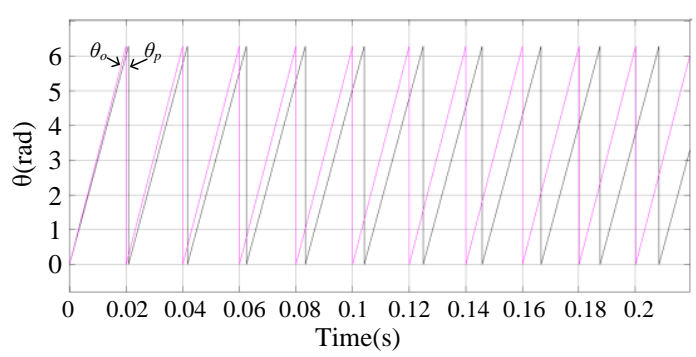

Fig. 6. Phase $\theta_{o}$ and $\theta_{p}$.

The traditional pre-synchronization control strategy is shown in Fig. 8. The inverter output voltage phase $\theta_{\mathrm{o}}$ and the 
grid voltage phase $\theta_{\mathrm{p}}$ are obtained by the phase-locked loop PLL, and the phase difference $\Delta \theta$ is obtained by $\Delta \theta=\theta_{\mathrm{o}}-\theta_{\mathrm{p}}$. Through the PI controller, the output signal is limited and superimposed on the VSG frequency reference signal so that the VSG output voltage phase will track the grid voltage phase.

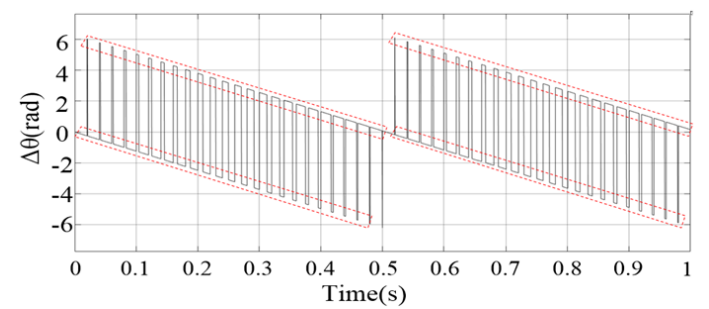

Fig. 7. Phase $\Delta \theta=\theta_{o}-\theta_{p}$.

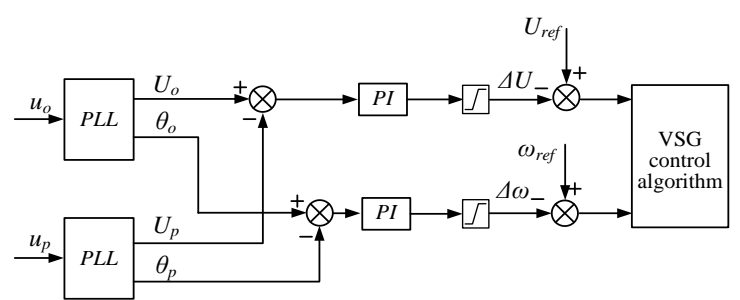

Fig. 8. Block diagram of the traditional pre-synchronization control.

From Fig. 6 and Fig. 7, it can be seen that the phase of VSG output voltage and grid voltage varies periodically in the range from 0 to $2 \pi$, and the phase difference $\Delta \theta$ has step change between positive sign and negative sign at the moment of $\omega t=2 k \pi(k=0,1,2, \ldots)$, denoting with red dot line. Therefore, using the traditional pre-synchronization control, not only high accuracy of the PLL is needed, but long pre-synchronization tracking time also. Moreover, designing the pre-synchronization control parameters is more difficult.

\section{Proposed Pre-Synchronization Control}

Although the $\Delta \theta$ has step changes between positive and negative signs at the moment of $\omega t=2 k \pi(k=0,1,2, \ldots)$, the $\sin \Delta \theta$ is still a continuous value because of $\sin (\Delta \theta \pm 2 k \pi)=$ $\sin \Delta \theta$. And when the value of $\Delta \theta$ is very small and close to 0 , there is $\sin \Delta \theta \approx \Delta \theta$. Based on this principle, and in order to avoid step changes of $\Delta \theta$ during the pre-synchronization control, the proposed pre-synchronization control can be derived by replacing $\Delta \theta$ with $\sin \Delta \theta$. Figure 9 shows the $\sin \Delta \theta$ curve corresponding to the phase difference $\Delta \theta$. Figure 10 shows comparison of the phase difference $\Delta \theta$ and the $\sin \Delta \theta$, where $\sin \Delta \theta$ is a continuous smooth curve, and the $\Delta \theta$ step change has no effect on the $\sin \Delta \theta$.

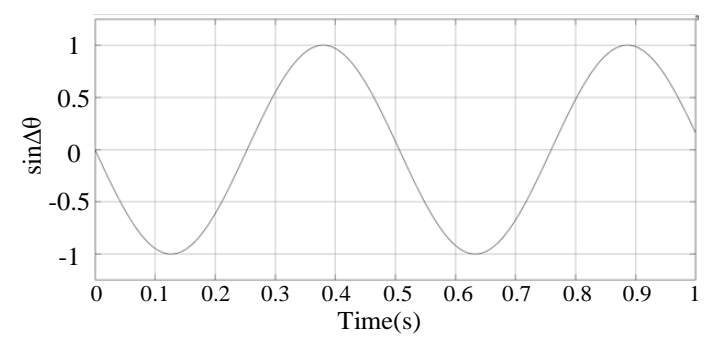

Fig. 9. Plot of $\sin \Delta \theta$.

In addition, when calculating $\Delta \theta$, a PLL needs to be introduced, which makes the pre-synchronization control system more complex. However, $\sin \Delta \theta$ can be calculated in the $\alpha \beta$ coordinate system, which eliminates PLLs and simplifies the control design. Figure 11 shows $\sin \Delta \theta$ calculation.

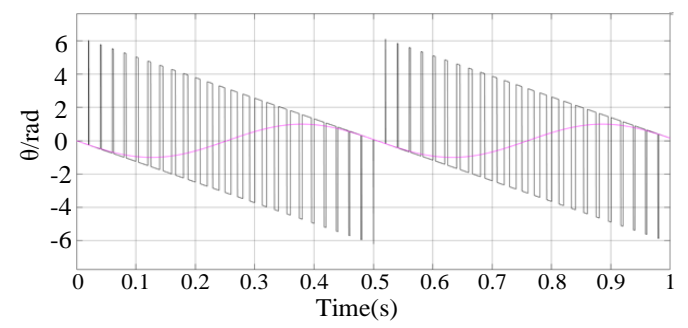

Fig. 10. Comparison of the phase difference $\Delta \theta$ and the $\sin \Delta \theta$.

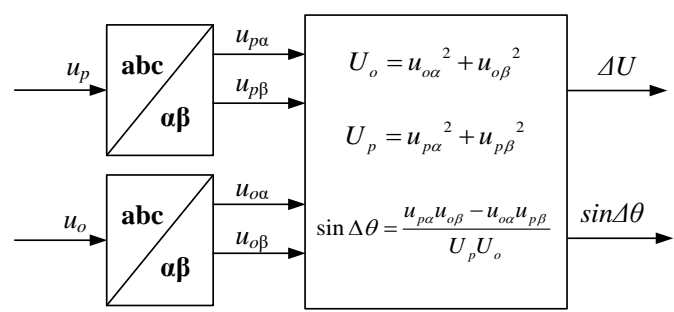

Fig. 11. Calculation of $\sin \Delta \theta$ in $\alpha \beta$ coordinate system.

In the proposed pre-synchronization control, $\sin \Delta \theta$ calculated in the $\alpha \beta$ coordinate system is sent to the PI controller instead of the phase difference $\Delta \theta$, then the output error signal is superimposed on the VSG given frequency. The implementation process of the algorithm in VSG control is shown in Fig. 12.

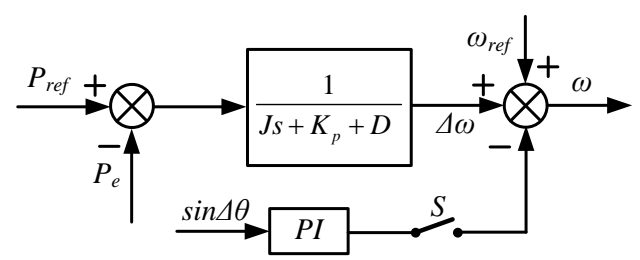

Fig. 12. Block diagram of the proposed phase pre-synchronization control.

The switch $S$ in Fig. 12 carries out implementation of the proposed phase pre-synchronization. Before the grid-tied contactor is closed, the switch $S$ is closed to start the pre-synchronization control. When the VSG output voltage is in phase with the grid voltage, the grid-tied contactor is closed, and then the switch $S$ is opened. After the above implementation, the VSG grid-tied connection is realized.

\section{MODEL AND SimUlation}

In order to verify the proposed VSG pre-synchronization control strategy, a $12 \mathrm{~kW}$ VSG simulation model is built under Matlab /Simulink, and its key parameters are shown in Table I. The parameters are used for the prototype.

TABLE I. VSG PARAMETERS.

\begin{tabular}{|c|c|c|c|}
\hline Parameters & Value & Parameters & Value \\
\hline $\begin{array}{c}\text { DC side voltage } \\
\text { Udc/V }\end{array}$ & 750 & $\begin{array}{c}\text { Inverter side } \\
\text { inductance } L 1 / \mathrm{mH}\end{array}$ & 1.4 \\
\hline $\begin{array}{c}\text { Grid phase voltage } \\
\text { Up/V }\end{array}$ & 220 & Filter capacitor C/ $\mu \mathrm{F}$ & 15 \\
\hline $\begin{array}{c}\text { Rated output power } \\
\text { Po/kW }\end{array}$ & 12 & $\begin{array}{c}\text { Grid side inductance } \\
L 2 / \mathrm{mH}\end{array}$ & 1.4 \\
\hline
\end{tabular}




\begin{tabular}{|c|c|c|c|}
\hline Parameters & Value & Parameters & Value \\
\hline Moment of inertia/J & 28.7 & $\begin{array}{c}\text { Droop coefficient of } \\
\text { reactive power } K \mathrm{q}\end{array}$ & 386 \\
\hline $\begin{array}{c}\text { Droop coefficient of } \\
\text { active power } K \mathrm{p}\end{array}$ & 1911 & IGBT switch module & $\begin{array}{c}\text { Mitsubishi } \\
\text { PM75RL1A120 }\end{array}$ \\
\hline $\begin{array}{c}\text { Switching frequency } \\
f \mathrm{sw} / \mathrm{kHz}\end{array}$ & 10 & DSP controller & TMS320F28335 \\
\hline
\end{tabular}

The key simulation waveforms are presented in Fig. 13. In the simulation, the VSG given power $P_{\text {ref }}=12 \mathrm{~kW}$, and the local load active power is $6 \mathrm{~kW}$. The pre-synchronization control is activated at $0.2 \mathrm{~s}$, and the grid connection is at $0.3 \mathrm{~s}$.

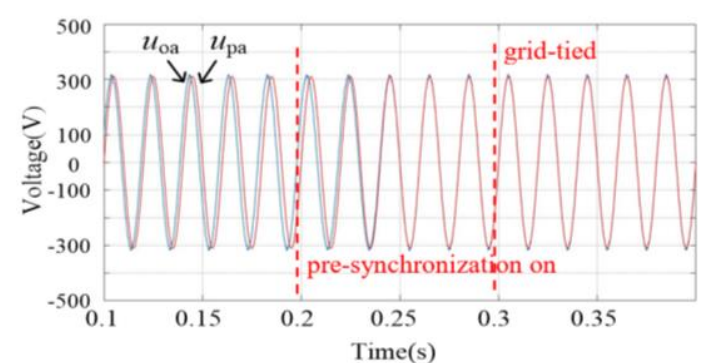

(a)

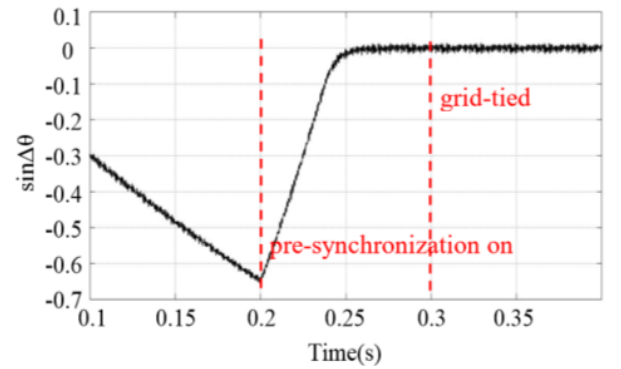

(b)

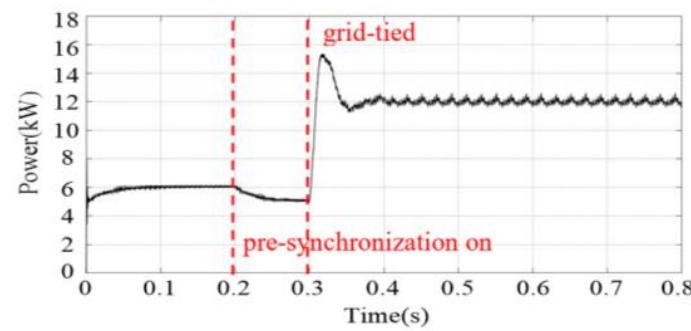

(c)

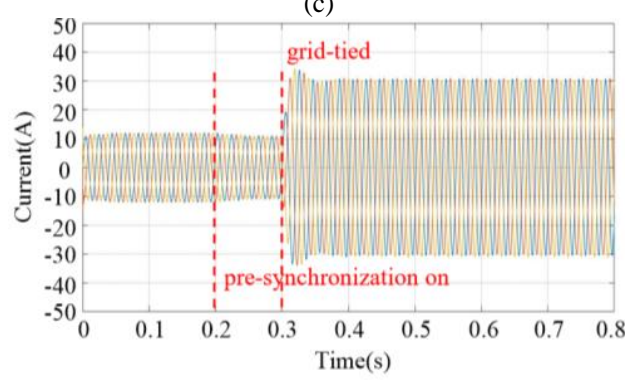

(d)

Fig. 13. Key simulation waveforms of the VSG under disconnection/grid-tied switching process: (a) VSG output A-phase voltage uoa and grid A-phase voltage upa under Upa $=220 \mathrm{Vac}$; (b) Phase difference between VSG output voltage and grid voltage; (c) The VSG output active power; (d) VSG output three-phase current.

Figure 13(a) shows the VSG A-phase voltage $u_{\text {oa }}$ waveform and the grid A-phase voltage $u_{\mathrm{pa}}$. It can be that there is obvious phase difference before the pre-synchronous happening because the VSG output voltage frequency is different from the power grid frequency. When the pre-synchronization enables, the VSG output voltage phase starts to track the power grid voltage phase, and the two waveforms match quickly.

Figure 13(b) plots $\sin \Delta \theta$. The simulation results show that the phase difference $\Delta \theta$ is 0 within $0.05 \mathrm{~s}$ after enabling the pre-synchronization control at $0.2 \mathrm{~s}$. The simulation results show the effectiveness and tracking rapidly of the proposed pre-synchronization control strategy.

Figure 13(c) and Figure 13(d) are the VSG output active power curve and the three-phase current waveform of the VSG, respectively. The simulation results show that the VSG realizes the seamless switching from off-grid to grid connection and it can operate stably after grid connection.

\section{EXPERIMENTS}

A VSG prototype with the parameters of Table I is built to further verify the proposed pre-synchronization control strategy and design. The experiment platform is shown in Fig. 14. The experiment working conditions are the same as of the simulations.
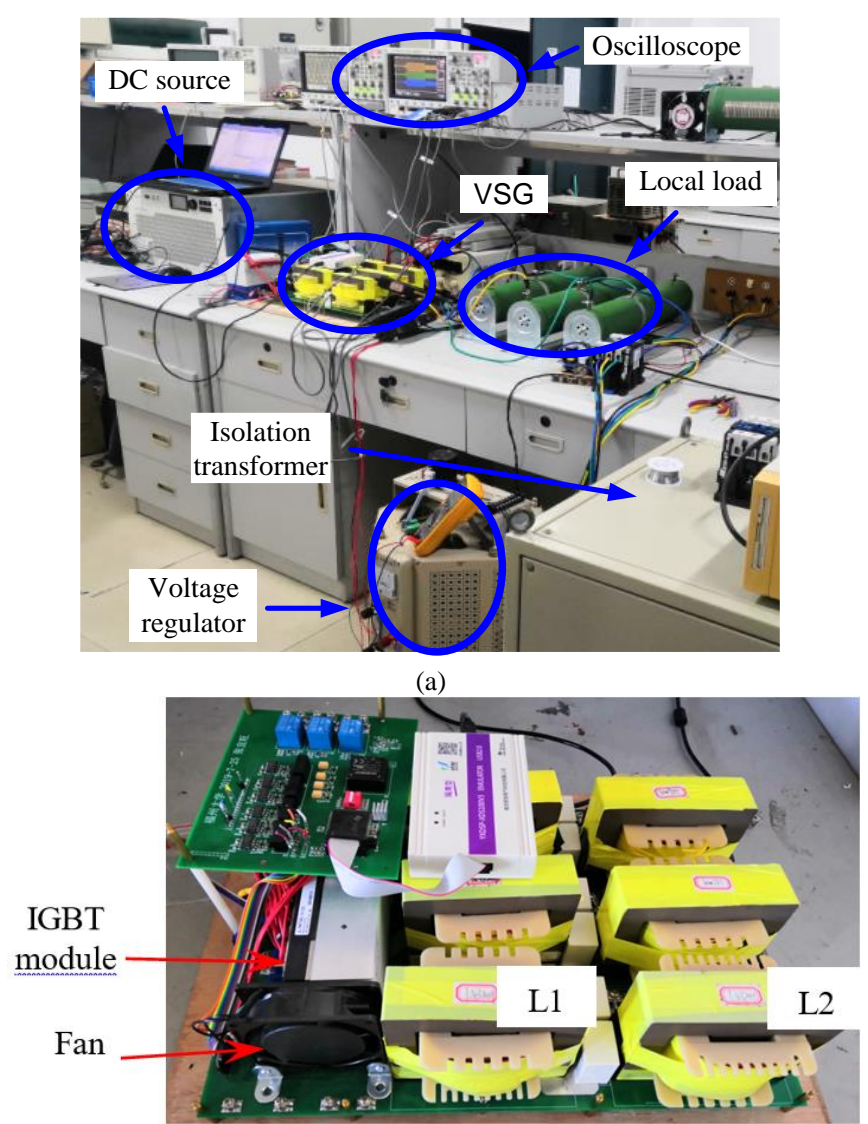

(b)

Fig. 14. (a) The VSG experiment platform and (b) the VSG prototype.

In Fig. 15(a), $u_{\mathrm{oa}}$ is the VSG A-phase output voltage and $u_{\mathrm{pa}}$ is the grid A-phase voltage. It shows that the VSG output voltage can track the grid voltage in phase quickly.

Figure 15(b) shows the VSG output three-phase current waveform with switch transition, and there is small current or power impact under the proposed pre-synchronization control strategy when the VSG is connected to the grid. After the pre-synchronization control is disabled, the VSG current or power rises to reach the given value under control of the frequency controller. After the grid-tied, the output power of VSG can still track the new given value and run stably. 


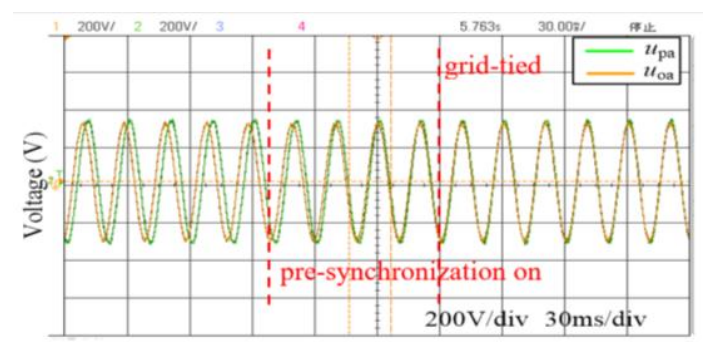

Time (ms)

(a)

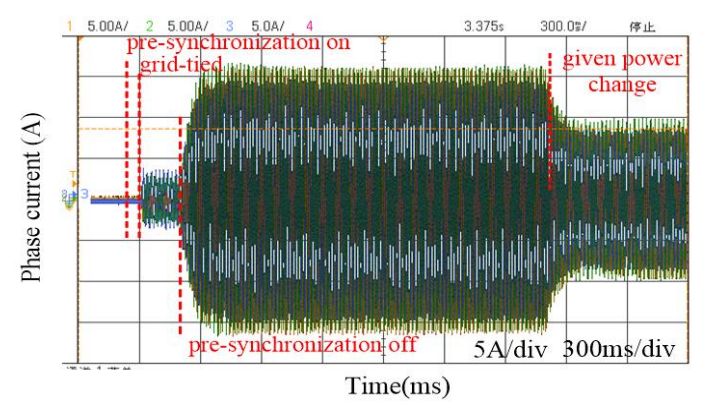

(b)

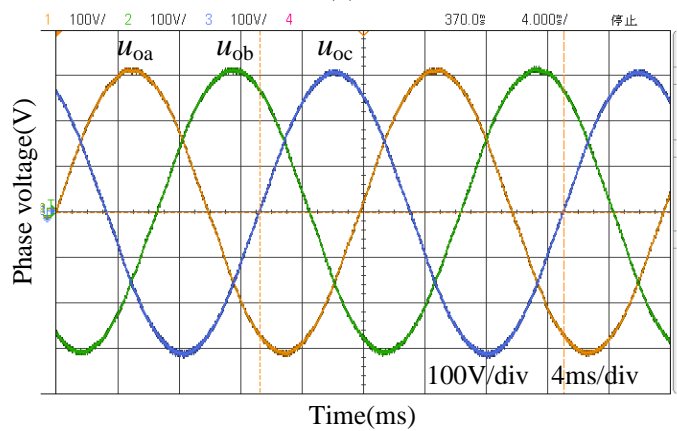

(c)

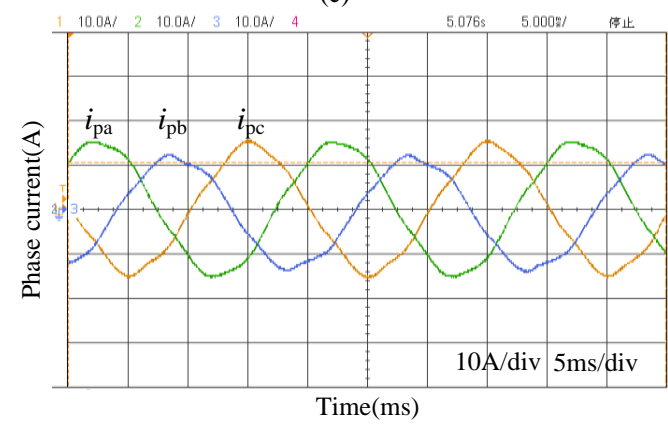

(d)

Fig. 15. Key waveforms of the VSG with grid connection: (a) Key waveforms of VSG output A-phase voltage and grid A-phase voltage under $\mathrm{U}_{\mathrm{pa}}=220 \mathrm{Vac}$; (b) The VSG three-phase output current during switch transition; (c) Key waveforms of the VSG three-phase steady state output voltage under grid-tied and full load output.; (d) Key waveform of the VSG three-phase steady state current under grid-tied and full load output.

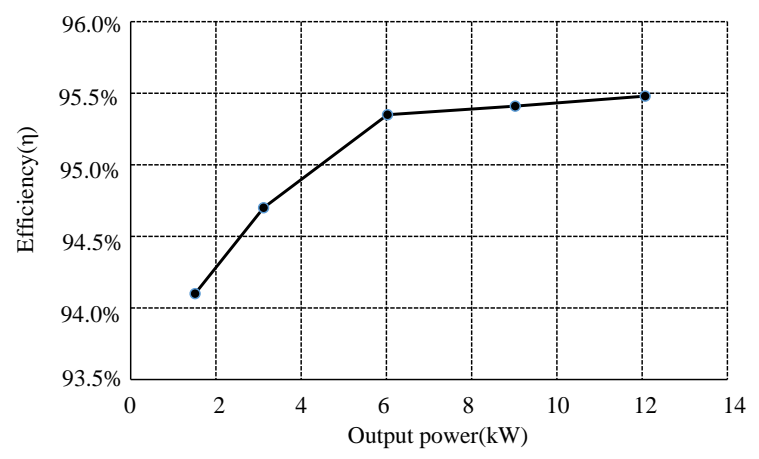

Fig. 16. The VSG prototype efficiency curve.

Figure 15(c) and Figure 15(d) show the steady-state waveforms of the VSG output voltage and grid-tied current under full load. It has low voltage and current total harmonic distortation (THD), and the current THD is about $6.6 \%$.

The VSG prototype efficiency curve is shown in Fig.16, and its efficiency is above $94 \%$ under most of output power.

\section{CONCLUSIONS}

The VSG or the grid-tied inverter provides the droop characteristics and the moment of inertia, and thereby takes part in the grid frequency and voltage regulation. However, the phase difference between the VSG voltage and the grid voltage at the grid-tied moment may produce large inrush power and damage the VSG. Therefore, the pre-synchronization control to minimize the phase difference must be carried out.

The proposed pre-synchronization control is implemented by replacing the phase difference $\Delta \theta$ with $\sin \Delta \theta$. Because $\sin \Delta \theta$ changes smoothly and can be calculated in $\alpha \beta$ coordinate system, the control can be realized more easily without PLLs. However, the traditional pre-synchronization control depends on high accuracy of PLL to get the phase difference, and has $\Delta \theta$ with step changes.

The built $12 \mathrm{~kW}$ VSG prototype has short pre-synchronization tracking time and high accuracy resulting in low inrush power at the moment of grid connection. It also has low voltage, current THD and high efficiency, and operates stably under the whole range of load. The simulation and experiments verify the proposed pre-synchronization control and its associated design.

\section{CONFLICTS OF INTEREST}

The authors declare that they have no conflicts of interest.

\section{REFERENCES}

[1] S. Hong, C. Fan, S. Cheng et al., "Research on fault equivalence method for multiple inverter-interfaced distributed generation based on PQ control strategy", Power System Technology, vol. 42, no. 4, pp. 1101-1109, 2018. DOI: 10.13335/j.1000-3673.pst.2017.2391.

[2] X. Wu, L. Zuo, J. Yi, and L. Han, “A double closed-loop control strategy for LCL-type grid-connected inverter based on combination state feedback", in Proc. of 2016 International Conference on Smart Grid and Clean Energy Technologies (ICSGCE), Chengdu, 2016, pp. 359-363. DOI: 10.1109/ICSGCE.2016.7876084.

[3] H. Han, Y. Liu, Y. Sun, M. Su, and J. M. Guerrero, "An improved droop control strategy for reactive power sharing in islanded microgrid", IEEE Transactions on Power Electronics, vol. 30, no. 6, pp. 3133-3141, Jun. 2015. DOI: 10.1109/TPEL.2014.2332181.

[4] X. Meng, J. Liu, and Z. Liu, "A generalized droop control for grid-supporting inverter based on comparison between traditional droop control and virtual synchronous generator control", IEEE Transactions on Power Electronics, vol. 34, no. 6, pp. 5416-5438, Jun. 2019. DOI: 10.1109/TPEL.2018.2868722.

[5] H. Wu, X. Ruan, D. Yang et al., "Small-signal modeling and parameters design for virtual synchronous generators", IEEE Transactions on Industrial Electronics, vol. 63, no. 7, pp. 4292-4303, Jul. 2016. DOI: 10.1109/TIE.2016.2543181.

[6] J. Zakis, E. Makovenko, H. Zeng, O. Husev, and L. Kutt, "qZS inverter as syn-chronverter in small-scale micro-grid", Elektronika ir Elektrotechnika, vol. 24, no. 2, pp. 58-62, 2018. DOI: 10.5755/j01.eie.24.2.20636.

[7] J. Driesen and K. Visscher, "Virtual synchronous generators", in Proc of 2008 IEEE Power and Energy Society General Meeting Conversion and Delivery of Electrical Energy in the 21st Century, Pittsburgh, PA, 2008, pp. 1-3. DOI: 10.1109/PES.2008.4596800.

[8] M. Zhang, M. Liu, X. Zheng, H. Li, Y. Yu, and Z. Li, "Research on pre-synchronization control strategy for microgrid VSG inverter", in Proc. of 2019 14th IEEE Conference on Industrial Electronics and 
Applications (ICIEA), Xi'an, China, 2019, pp. 1587-1592. DOI: 10.1109/ICIEA.2019.8834104.

[9] P. Xing, X. Jia, C. Tian, Y. Mao, L. Yu, and X. Jiang, "Pre-synchronization control method of birtual synchronous generator with alterable inertia", in Proc. of 2019 IEEE 10th International Symposium on Power Electronics for Distributed Generation Systems $(P E D G), \quad X i$ 'an, China, 2019, pp. 142-146. DOI: 10.1109/PEDG.2019.8807766

[10] L. Yang, C. Wang, Z. Lü et al., "The method of pre-synchronized grid-connection of synchronverter", Power System Technology, vol. 38, no. 11, pp. 3103-3108, 2014. DOI: 10.13335/j.1000-3673.pst.2014.11.024.

[11] R. Shi, X. Zhang, H. Xu et al., "The active and reactive power control of virtual synchronous generator based on adaptive mode switching", Transactions of China Electrotechnical Society, vol. 33, no. 12, pp. 127-137, 2017. DOI: 10.19595/j.cnki.1000-6753.tces.2017.12.013.

[12] X. Yan, D. Wang, and J. Jia, "Communication free pre-synchronization grid connection scheme of virtual synchronous generator based on distributed micro grid", Transactions of China Electrotechnical Society, vol. $34, \quad$ no. $19, \quad$ pp. $4143-4153,2019 . \quad$ DOI: 10.19595/j.cnki.1000-6753.tces.180765.

[13] Q.-Ch. Zhong and G. Weiss, "Synchronverters: Inverters that mimic synchronous generators", IEEE Transactions on Industrial Electronics, vol. 58, no. 4, pp. 1259-1267, Apr. 2011. DOI: 10.1109/TIE.2010.2048839.

[14] X. Meng, J. Liu, and Z. Liu, "A generalized droop control for grid-supporting inverter based on comparison between traditional droop control and virtual synchronous generator control", IEEE Transactions on Power Electronics, vol. 34, no. 6, pp. 5416-5438, Jun. 2019. DOI: 10.1109/TPEL.2018.2868722.

[15] Q. Shi, G. Wang, L. Fu et al., "A design method of simulative synchronous generator based on virtual synchronous generator theory", Power System Technology, vol. 39, no. 3, pp. 783-790, 2015. DOI 10.13335/j.1000-3673.pst.2015.03.030.

[16] J. Liu, Y. Miura, and T. Ise, "Comparison of dynamic characteristics between virtual synchronous generator and droop control in inverter-based distributed generators", IEEE Transactions on Power Electronics, vol. 31, no. 5, pp. 3600-3611, May 2016. DOI: 10.1109/TPEL.2015.2465852.

This article is an open access article distributed under the terms and conditions of the Creative Commons Attribution 4.0 (CC BY 4.0) license (http://creativecommons.org/licenses/by/4.0/) 